\title{
MR and CT imaging of pulmonary valved conduits in children and adolescents: normal appearance and complications
}

\author{
Estelle V. Tenisch • Leonor T. Alamo • Nicole Sekarski • \\ Michel Hurni • François Gudinchet
}

Received: 19 October 2013 / Revised: 3 March 2014 / Accepted: 14 May 2014 / Published online: 17 July 2014

(C) Springer-Verlag Berlin Heidelberg 2014

\begin{abstract}
Background The Contegra ${ }^{\circledR}$ is a conduit made from the bovine jugular vein and then interposed between the right ventricle and the pulmonary artery. It is used for cardiac malformations in the reconstruction of right ventricular outflow tract.

Objective To describe both normal and pathological appearances of the Contegra ${ }^{\circledR}$ in radiological imaging, to describe imaging of complications and to define the role of CT and MRI in postoperative follow-up.

Materials and methods Forty-three examinations of 24 patients (17 boys and 7 girls; mean age: 10.8 years old) with Contegra ${ }^{\circledR}$ conduits were reviewed. Anatomical description and measurements of the conduits were performed. Pathological items examined included stenosis, dilatation, plicature or twist, thrombus or vegetations, calcifications and valvular regurgitation. Findings were correlated to the echographic gradient through the conduit when available.

Results CT and MR work-up showed Contegra ${ }^{\circledR}$ stenosis $(n=$ 12), dilatation $(n=9)$ and plicature or twist $(n=7)$. CT displayed
\end{abstract}

E. V. Tenisch $(\bowtie)$

Department of Medical Imaging,

Lausanne University Hospital,

rue du Bugnon 46, 1012 Lausanne, Switzerland

e-mail: estelle.tenisch@gmail.com

L. T. Alamo $\cdot$ F. Gudinchet

Department of Medical Imaging,

Lausanne University Hospital,

rue du Bugnon 46, 1011 Lausanne, Switzerland

N. Sekarski

Department of Pediatrics,

Lausanne University Hospital,

rue du Bugnon 46, 1011 Lausanne, Switzerland

\section{Hurni}

Department of Cardiovascular Surgery,

Lausanne University Hospital,

rue du Bugnon 46, 1011 Lausanne, Switzerland thrombus or vegetations in the Contegra ${ }^{\circledR}$ in three clinically infected patients. Calcifications of the conduit were present at $\mathrm{CT}$ in 12 patients and valvular regurgitation in three patients. The comparison between CT and/or MR results showed a good correlation between the echographic gradient and the presence of stenosis in the Contegra ${ }^{\circledR}$.

Conclusion $\mathrm{CT}$ and MR bring additional information about permeability and postoperative anatomy especially when echocardiography is inconclusive. Both techniques depict the normal appearance of the conduit, and allow comparison and precise evaluation of changes in the postoperative follow-up.

Keywords Congenital heart disease $\cdot$ Heart valve disease . Right ventricular outflow tract obstruction $\cdot$ Child

\section{Introduction}

Many congenital cardiac malformations are the result of an abnormal formation of the right ventricular outflow tract (RVOT). Currently, RVOT reconstruction requires that a conduit be interposed between the right ventricle and the pulmonary artery bifurcation [1]. This conduit can be prosthetic (i.e. heterografts), made of cryopreserved homograft (i.e. cadaveric) or xenograft tissue. The Contegra ${ }^{\circledR}$, a pulmonary valved conduit, represents a commercially available xenograft model.

This conduit is made from the bovine jugular vein, which naturally contains a tricuspid valve. The valve and its sinus are located at the middle of the vein. The Contegra ${ }^{\circledR}$ conduit is supplied with or without an external semirigid ring at the valve annulus. In the United States, the FDA approved its use in 2003. In our institution, we first began implanting the conduit in 1999. Contegra ${ }^{\circledR}$ implantation is essentially used in congenital heart diseases requiring RVOT reconstruction, such as pulmonary stenosis, pulmonary regurgitation, tetralogy of Fallot, truncus arteriosus, transposition with ventricular 
septal defect (VSD) and pulmonary atresia, and in the Ross procedure. It may also replace previously implanted, but dysfunctional, pulmonary homografts or valved conduits [2].

The Contegra ${ }^{\circledR}$ has only been recently used in paediatric cardiovascular surgery. Clinical and echographic results have been published from a paediatric cardiologist point of view about the qualities of the conduit [3-6]. However, as far as we know, imaging characteristics of normal and pathological valved conduits from a radiologist's point of view have rarely been described. In our institution, CT and MRI have won recognition as appropriate imaging methods before and after Contegra ${ }^{\circledR}$ implantation in various situations: suspicion of conduit stenosis at echography, follow-up, anatomy evaluation and measurements of the conduit and of the pulmonary arteries. CT and MRI can indeed bring relevant additional information to US, and may prevent or help with planning an invasive procedure.

The purpose of this study was to describe the normal appearance of a Contegra ${ }^{\circledR}$ conduit using CT and MRI and to depict early and late complications that may appear in patients after conduit implantation. We tried to define the role of CT and MRI not only in the standard follow-up but also in case of complications.

\section{Materials and methods}

The ethical committee was informed about the study but being a retrospective comparison between two methods, no further evaluation was required.

Patient population

A search in the radiological database of the department of radiology between January 1999 and July 2013 showed 24 young patients referred for imaging after Contegra ${ }^{\circledR}$ placement. Inclusion criteria for the study were thorax CT or cardiac MRI performed in young patients ( $<25$ years) with Contegra ${ }^{\circledR}$ implantation. We retrospectively reviewed 43 radiological exams (24 CT and $13 \mathrm{MRI}$ ) performed on 24 patients (17 males and 7 females). At the time of the radiological examination, mean age and median were 10 years and 8 months and 14 years and 7 months, respectively (range: 1 to 22 years old). Mean time between Contegra ${ }^{\circledR}$ implantation and imaging was 3 years and 7 months (median: 4 years). Postoperative follow-up ranged from 1 day to 6 years. The indications for radiological exams and the main cardiac anomalies are listed in Table 1.

\section{Surgical technique}

The technique for RVOT reconstruction was the same for all patients. All Contegra ${ }^{\circledR}$ conduits were rinsed with manual agitation three times in $500 \mathrm{ml}$ of saline before implantation to remove glutaraldehyde, which is an element of the manufacturing process. No ring-supported Contegra ${ }^{\circledR}$ conduit was inserted. The conduits were cut as short as possible to avoid kinking between proximal and distal anastomosis. The proximal anastomosis was performed in a "hood shape" and the distal section of the tube was oblique to increase the area of anastomosis in an attempt to reduce further anastomotic narrowing.

\section{CT protocols}

Data were acquired on a 64-detector CT system (Lightspeed VCT; General Electric Medical System, Milwaukee, USA).

For ECG-gated CT, patients received oral beta blockers 30 to $60 \mathrm{~min}$ before the examination. Acquisitions were obtained after an antecubital intravenous injection of $1.5-2 \mathrm{ml} / \mathrm{kg}$ nonionic contrast medium (Accupaque 300 or 350; GE Healthcare, Giles, UK), with $10-20 \mathrm{ml}$ saline solution as bolus chaser. Helical CT acquisition was started during a single breath hold when contrast enhancement of at least $200 \mathrm{HU}$ was detected in the right cavities (bolus tracking). Prospective acquisitions were preferred for radiation protection reasons. However, they were mainly performed in older patients and were not always possible in young children because of their faster heart rates. When a retrospective acquisition was performed, ECG-gated axial transverse reconstructions of 1.25 -mm slices were obtained at $10 \%$ through $90 \%$ at $10 \%$ intervals of the R-R cycle. Twodimensional reconstructions were always used for measurements and 3-D reconstructions (Advantage Windows workstation, 4.3, General Electric Medical System, Milwaukee, USA) were made when necessary.

For non-gated $\mathrm{CT}$, acquisition was made after antecubital injection of 1.5 to $2 \mathrm{ml} / \mathrm{kg}$ of non-ionic contrast medium (Accupaque 300; GE Healthcare, Giles, UK). Helical acquisition started $25 \mathrm{~s}$ after injection or with the Smart prep technique described above. Breath hold was asked when possible. Table 2 summarizes the 64-detector row CT protocols that were used with subsequent CT dose index (CTDI) and dose-length product (DLP) values.

\section{MRI protocols}

The cardiac studies were performed on a 1.5-T scanner (Magnetom Symphony; Siemens, Erlangen, Germany) using a body coil. MR protocols are summarized in Table 3. The first sequence was an axial ultrafast spin-echo sequence (HASTE) covering the entire thorax. Then, cine images were obtained using ECG-gated multislice gradient echo sequences in various planes: short axis, 2-chamber view, right ventricular outflow tract (RVOT), long axis and 4-chamber view. Finally, contrastenhanced-MR angiography (CE-MRA) and post-gadolinium ultrafast gradient echo (VIBE) coronal, axial and sagittal views were obtained. Depending on the suspicion of pulmonary valve regurgitation, the examination was completed using velocity- 
Table 1 Patients' main cardiac anomalies and indication for examination

\begin{tabular}{|c|c|c|c|c|}
\hline Patient & Age & Gender & Cardiac anomaly & Indication for radiological examination \\
\hline \multirow[t]{3}{*}{1} & $9 Y$ & $\mathrm{~F}$ & Aortic valvular stenosis with Ross operation & Suspicion of Contegra ${ }^{\mathbb{R}}$ stenosis \\
\hline & $11 \mathrm{Y}$ & & & Control after Contegra ${ }^{\circledR}$ stenting \\
\hline & $12 \mathrm{Y}$ & & & Control after Contegra ${ }^{\circledR}$ stenting \\
\hline \multirow[t]{3}{*}{2} & $10 \mathrm{Y}$ & M & Tetralogy of Fallot & Suspicion of Contegra ${ }^{\circledR}$ stenosis \\
\hline & $15 \mathrm{Y}$ & & & Evaluation of Contegra ${ }^{\circledR}$ stenosis \\
\hline & $15 \mathrm{Y}$ & & & Measurements of Contegra ${ }^{\circledR}$ stenosis \\
\hline \multirow[t]{4}{*}{3} & $15 \mathrm{Y}$ & $\mathrm{F}$ & Aortic valvular stenosis with Ross operation & Follow-up \\
\hline & $16 \mathrm{Y}$ & & & Follow-up \\
\hline & $17 \mathrm{Y}$ & & & Follow-up \\
\hline & $18 \mathrm{Y}$ & & & Follow-up \\
\hline 4 & $3 \mathrm{Y}$ & M & Double outlet right ventricle & Evaluation of anatomy \\
\hline 5 & $15 \mathrm{Y}$ & M & Aortic valvular stenosis with Ross operation & Suspicion of pulmonary embolism \\
\hline \multirow[t]{3}{*}{6} & $8 \mathrm{Y}$ & M & $\begin{array}{l}\text { Pulmonary atresia with ventricular septal defect } \\
\text { (PA-VSD) }\end{array}$ & Evaluation of anatomy \\
\hline & $12 \mathrm{Y}$ & & & Measurements of Contegra ${ }^{\circledR}$ \\
\hline & $14 \mathrm{Y}$ & & & Control after Contegra ${ }^{\circledR}$ stenting \\
\hline 7 & $7 \mathrm{Y}$ & $\mathrm{F}$ & Truncus arteriosus & Suspicion of Contegra ${ }^{\circledR}$ stenosis \\
\hline 8 & $22 \mathrm{Y}$ & M & $\begin{array}{l}\text { Pulmonary atresia with ventricular septal defect } \\
\text { (PA-VSD) }\end{array}$ & Evaluation of anatomy \\
\hline 9 & $1 \mathrm{Y}$ & M & Double outlet right ventricle & $\begin{array}{l}\text { Suspicion of pulmonary embolism and assessment of stent } \\
\text { position in the pulmonary artery }\end{array}$ \\
\hline \multirow[t]{2}{*}{10} & $10 \mathrm{Y}$ & M & Tetralogy of Fallot & Assessment of anatomy \\
\hline & $10 \mathrm{Y}$ & & & Postoperative control \\
\hline \multirow[t]{2}{*}{11} & $12 \mathrm{y}$ & M & Tetralogy of Fallot & Assessment of pulmonary vascular anatomy \\
\hline & $15 \mathrm{Y}$ & & & Follow-up \\
\hline 12 & $3 \mathrm{Y}$ & M & Tetralogy of Fallot & Search for pulmonary oedema or pneumonia \\
\hline \multirow[t]{4}{*}{13} & $2 \mathrm{M}$ & M & Transposition of the Great Arteries (TGA) & Assessment of Contegra ${ }^{\circledR}$, infection \\
\hline & $2 \mathrm{M}$ & & & Suspicion of endocarditis \\
\hline & $4 \mathrm{Y}$ & & & Search for remaining septal defect \\
\hline & $5 \mathrm{Y}$ & & & Suspicion of pulmonary embolism \\
\hline 14 & $15 \mathrm{Y}$ & M & Aortic valvular stenosis with Ross operation & Evaluation of coronary anatomy \\
\hline \multirow[t]{2}{*}{15} & $9 Y$ & $\mathrm{~F}$ & Tetralogy of Fallot & Postoperative control \\
\hline & $16 y$ & & & Pneumonia \\
\hline 16 & $2 \mathrm{y}$ & $\mathrm{F}$ & Tetralogy of Fallot & Hemothorax \\
\hline 17 & $7 \mathrm{Y}$ & $\mathrm{F}$ & Tetralogy of Fallot & Mediastinitis \\
\hline \multirow[t]{5}{*}{18} & $15 \mathrm{Y}$ & M & Tetralogy of Fallot & Suspicion of Contegra ${ }^{\circledR}$ stenosis \\
\hline & $15 \mathrm{Y}$ & & & Suspicion of Contegra ${ }^{\mathbb{R}}$ stenosis \\
\hline & $15 \mathrm{Y}$ & & & Control after Contegra ${ }^{\mathbb{R}}$ stenting \\
\hline & $16 \mathrm{Y}$ & & & Follow-up \\
\hline & $17 \mathrm{Y}$ & & & Follow-up \\
\hline 19 & $16 \mathrm{Y}$ & M & Aortic valvular stenosis with Ross operation & Endocarditis \\
\hline 20 & $17 \mathrm{Y}$ & $\mathrm{F}$ & Tetralogy of Fallot & Dyspnoea, SVE \\
\hline 21 & $1 \mathrm{Y}$ & M & Double outlet right ventricle & Pulmonary hypertension, suspicion of Contegra ${ }^{\circledR}$ stenosis \\
\hline 22 & $18 \mathrm{Y}$ & M & Aortic valvular stenosis with Ross operation & Retrosternal chest pain unrelated to effort \\
\hline 23 & $4 \mathrm{Y}$ & M & Tetralogy of Fallot (TOF) & Endocarditis \\
\hline 24 & $2 \mathrm{Y}$ & M & Truncus arteriosus & Suspicion of Contegra ${ }^{\mathbb{R}}$ stenosis \\
\hline
\end{tabular}


Table 2 64-detector CT acquisition protocols

\begin{tabular}{|c|c|c|c|c|}
\hline Age (year)/weight (kg) & $0-1 /<10$ & $1-6 / 10-25$ & $6-12 / 25-40$ & $>12 />40$ \\
\hline Scout view AP+lateral $120 \mathrm{kVp}, 10 \mathrm{~mA}$ & + & + & + & + \\
\hline \multicolumn{5}{|l|}{ Non-gated scan } \\
\hline Gantry rotation time & 0.5 & 0.5 & 0.5 & 0.5 \\
\hline Pitch & 1.375 & 1.375 & 1.375 & 1.375 \\
\hline Recon. slice thickness (mm) & 2.5 & 2.5 & 2.5 & 2.5 \\
\hline Matrix size & $512 \times 512$ & $512 \times 512$ & $512 \times 512$ & $512 \times 512$ \\
\hline Field of view & $180 \times 80$ & $200 / 200$ & $180 / 180-250 \times 250$ & $240 \times 240-300 \times 300$ \\
\hline $\mathrm{kVp} / \mathrm{mA}$ & $100 / 120$ & $100 / 100-450$ & $100-120 / 180-450$ & $100-120 / 150-200$ \\
\hline CTDIw (mGy) & $1.5-2.2$ & $2.6-8$ & 5 & $5-14$ \\
\hline DLP (mGycm) & 40 & $50-190$ & $100-200$ & $200-290$ \\
\hline \multicolumn{5}{|l|}{ Smart prep $100 \mathrm{kVp} / 10 \mathrm{~mA}$} \\
\hline CTDIw (mGy)/DLP (mGy) & & $2.2-3 / 1.1-1.5$ & $2.5 / 1.3$ & $3-5 / 1.5-2.5$ \\
\hline \multicolumn{5}{|l|}{ Gated scan } \\
\hline Gantry rotation time (s) & & & 0.5 & 0.5 \\
\hline Pitch & & & 1.375 & 1.375 \\
\hline Recon. slice thickness (mm) & & & 0.625 & 0.625 \\
\hline Matrix size & & & $512 \times 512$ & $512 \times 512$ \\
\hline Field of view & & & $180 \times 180-250 \times 250$ & $240 \times 240-300 \times 300$ \\
\hline $\mathrm{kVp} / \mathrm{mA}$ & & & $100-120 / 250-750$ & $100-120 / 700$ \\
\hline CTDIw (mGy) & & & 50 & $70-85$ \\
\hline \multirow[t]{2}{*}{ DLP (mGycm) } & & & 1,300 & $1,830-2,200$ \\
\hline & & & M- & $\mathrm{M}+$ \\
\hline
\end{tabular}

$M+$ with ECG-controlled tube current modulation algorithm (ECG pulsing)

$M$ - without ECG-controlled tube current modulation algorithm

encoded cine GRE (phase contrast) sequences. Slice thickness was $4-8 \mathrm{~mm}$ with a $3-\mathrm{mm}$ gap. Field of view and image matrix essentially depended on patient size. A double dose, $0.2 \mathrm{mmol} /$ $\mathrm{kg}$ body weight $[7,8]$, of gadolinium-based contrast material (Dotarem ${ }^{\circledR}$ gadoterate meglumine; Guerbet AG, France) was injected with a mechanical injector pump in an antecubital intravenous line, followed by $10-20 \mathrm{ml}$ of saline solution. For the CE-MRA sequence, the bolus detection method (CARE bolus, Siemens, Erlangen, Germany) was always used. Studies were performed without anaesthesia, when the patient was old

Table 3 MRI protocols

\begin{tabular}{|c|c|c|c|c|c|c|}
\hline & Localizer & Ultrafast axial & $\begin{array}{l}\text { Cine MRI ( } 2,3 \text { and } 4 \\
\text { cavities and RVOT) }\end{array}$ & CE- MRA & Phase contrast (RVOT ) & Post-gadolinium sequence \\
\hline & bSSFP & HASTE & bSSFP & FLASH 3-D & PC-FLASH & FLASH 3-D \\
\hline Field of view & 250 to 300 & 300 & 200 to 250 & 300 & 300 to 340 & 300 to 400 \\
\hline Matrix & $128 \times 256$ & $128 \times 256$ & $134 \times 208$ & $208 \times 320$ & $192 \times 192$ & $125 \times 320$ \\
\hline Breath hold & - & + & + & + & + & + \\
\hline Cardiac gating & - & + & + & + & + & + \\
\hline TR/TE (ms) & $250 / 1.3$ & $700 / 400$ & $43 / 1.4$ & $3.3 / 1.1$ & $42 / 3$ & $4.5 / 2.2$ \\
\hline Flip angle & 80 & 160 & 80 & 25 & 20 & 10 \\
\hline Slice thickness (mm) & 5 & 5 to 8 & 4 to 8 & 0.9 & 4 to 6 & 3 \\
\hline Number of signal averages & 1 & 1 & 1 & 1 & 1 & 1 \\
\hline Acquisition time (s) & 20 & 20 & $7-10$ per slice & 15 & $10 \mathrm{~s}$ & $15 \mathrm{~s}$ \\
\hline
\end{tabular}

$R V O T$ right ventricular outflow tract, $C E-M R A$ contrast-enhanced MR angiography, $b S S F P$ balanced steady-state free precession, $H A S T E$ half-Fourier single-shot turbo spin-echo, $P C$ phase contrast, FLASH fast low angle shot 
enough to cooperate, generally 6 years old if mental status wasn't altered. Otherwise, the studies were done under general anaesthesia with intubation to obtain apnoea on demand.

The choice between CT and MRI was based on emergency level and the clinicians' interest about Contegra ${ }^{\circledR}$ calcification. MR was preferred in functional studies. CT was generally available more quickly. It is interesting to point out that no ECG-gated CT was performed on patients younger than 6 years of age because of concerns about radiation doses.

Image analysis

The CT and MR images were evaluated separately by two radiologists (F.G. and E.T.), who were blinded to the results of other imaging studies (US). In case of disagreement, final results were obtained by consensus between the two radiologists (F.G., 6 years experience and E.T., fellow with less than 1 year experience). The images were viewed on a workstation (Advantage windows software 4.3; GE Medical System, Milwaukee, USA) using 2-D (MIP, MPR) and 3-D (VR) reconstructions. Afterward, results were discussed with the paediatric cardiologists and paediatric cardiovascular surgeons.

The following imaging findings were reviewed:

In normal conduits: shape, diameter, length, wall thickness and wall calcifications, patency.

In abnormal conduits: stenosis, dilatation, plicature or twist of the conduit, thrombus, calcifications and valvular regurgitation.

Each item was evaluated in every radiological study, rated in a binary mode (present or absent) according to the findings. Stenosis, dilatation, plicature or twist and thrombus were assessed on CT and MR images. Although they were sometimes visible with MRI, we decided that calcifications were much more visible on CT and could only be evaluated with confidence using CT images. For obvious reasons, valvular regurgitation was only assessed with MR images.

To define the dilatation or stenosis of the Contegra ${ }^{\circledR}$, we considered as significant the values that were larger or smaller than $50 \%$ of the initial internal diameter of the conduit at the time of implantation. Both the smallest and the largest diameters of the conduit were measured, using reconstructions of cross-sectional planes on 3-D MR gadolinium-enhanced sequences [8].

\section{Results}

All patients underwent $\mathrm{CT}$ and MR without complications. Imaging findings are listed in Table 4.

A normal, recently implanted conduit appears as a thinwalled conduit binding the RVOT to the pulmonary trunk or one of its branches. The calibre is the same all along the conduit and corresponds to the diameter measured before implantation and given by the manufacturer. Graft walls are smooth and regular (Fig. 1). They are hypodense on $\mathrm{CT}$ and slightly thicker than those of the vessel to which they are anastomosed. Occasionally, surgical clips can be seen at both extremities and should not be confused with calcifications. Normal valve leaflets are not always visible, especially on MR. On CT, they can be depicted if they are closed during the acquisition time, which may be the case in CTs performed without gating or with a prospective ECG-gating [9]. Valves are sometimes detectable as thin, regular and symmetrical lines, forming the classical Mercedes-Benz ${ }^{\circledR}$ emblem on axial views.

Twelve gated CTs and 15 non-gated CTs were performed. Eight of the gated CTs were done with a retrospective ECGgating and four were done with a prospective ECG-gating.

In six patients, a normal Contegra ${ }^{\circledR}$ was depicted at least once (patients $3,10,11,16,20,22$ ). In the others, no abnormal findings were depicted. However, they were not considered normal because a valve or a stent had been implanted inside.

With CT, the Contegra ${ }^{\circledR}$ is more clearly depicted with gated acquisitions. In non-gated acquisitions, cardiac movement artefacts are always present, but they never prevent the readers from assessing the defined items.

With MR, the acquisition is always gated. Then, only the lower spatial resolution prevents from seeing the valve leaflets and the conduit's wall. However, like with CT, it is always possible to evaluate the defined items.

The complications are analysed separately. They are summarized in Table 5 .

The number of patients per complication is larger than the number of patients included in this study because the same patient can have more than one complication. In the 43 examinations, 17 showed no complications of the Contegra and 26 showed at least one complication. The 17 normal studies concerned 12 different patients. Those patients had radiological exams for follow-up (insufficient echogenicity) or as a baseline imaging after the insertion of a new Contegra.

Calcifications of the conduit were found in $11 \mathrm{CT}$ examinations in 11 patients. Hence, $46 \%$ of the patients having a CT in their medical records had a calcified Contegra ${ }^{\circledR}$. In patients with a calcified Contegra ${ }^{\circledR}$, the conduit had been in position for at least 1.5 years (mean time: 5 years) (Fig. 2). In our five patients with a previous endocarditis, four had a calcified Contegra ${ }^{\circledR}$. The one without calcification was suspected of a previous endocarditis, but it was never proved. Calcifications were responsible for a significant stenosis in only four patients.

Stenosis of the conduit were found in 10 patients $(41.7 \%)$ among 43 examinations. Generally, the stenosis had the following causes: plicature or twist of the Contegra ${ }^{\circledR}$ (two patients), calcifications (four patients) or parietal thickening due to known or suspected endocarditis (four patients). In three patients, the stenosis was associated with valvular regurgitation. Ultrasound 
Table 4 Imaging findings

\begin{tabular}{|c|c|c|c|c|c|c|}
\hline Patient & Age & Gender & $\begin{array}{l}\text { Age of } \\
\text { Contegra }^{\circledR}\end{array}$ & $\begin{array}{l}\text { Echocardiographic } \\
\text { gradient in } \mathrm{mm} \mathrm{Hg}\end{array}$ & $\begin{array}{l}\text { CT findings } \\
\text { Stenosis, dilatation, plicature/ twist, } \\
\text { thrombus/vegetations, calcification }\end{array}$ & $\begin{array}{l}\text { MR findings } \\
\text { Stenosis, dilatation, plicature/ twist, thrombus/ } \\
\text { vegetations, valvular regurgitation }\end{array}$ \\
\hline \multirow[t]{3}{*}{1} & $9 Y$ & $\mathrm{~F}$ & $4 \mathrm{Y}$ & 70 & & Stenosis \\
\hline & $11 \mathrm{Y}$ & & $6 \mathrm{Y}$ & 11.3 & & None \\
\hline & $12 \mathrm{Y}$ & & $7 \mathrm{Y}$ & 20 & & None \\
\hline \multirow[t]{3}{*}{2} & $10 \mathrm{Y}$ & M & $5 \mathrm{Y}$ & 50 & & Stenosis and valvular regurgitation \\
\hline & $15 \mathrm{Y}$ & & $10 \mathrm{Y}$ & 50 & & Stenosis and valvular regurgitation \\
\hline & $15 \mathrm{Y}$ & & $10 \mathrm{Y}$ & NA & Stenosis and calcification & \\
\hline \multirow[t]{4}{*}{3} & $15 \mathrm{Y}$ & $\mathrm{F}$ & $4 \mathrm{Y}$ & 15 & & None \\
\hline & $16 \mathrm{Y}$ & & $5 \mathrm{Y}$ & NA & & None \\
\hline & $17 \mathrm{Y}$ & & $6 \mathrm{Y}$ & 23 & & None \\
\hline & $18 \mathrm{Y}$ & & $7 \mathrm{Y}$ & 16 & & None \\
\hline 4 & $3 \mathrm{Y}$ & M & $2 \mathrm{Y}$ & 21 & & None \\
\hline 5 & $15 \mathrm{Y}$ & M & $5 \mathrm{Y}$ & 90 & Stenosis & \\
\hline \multirow[t]{3}{*}{6} & $8 \mathrm{Y}$ & M & $6 \mathrm{Y}$ & 37 & & Stenosis, dilatation and valvular regurgitation \\
\hline & $12 \mathrm{Y}$ & & $9 \mathrm{Y}$ & 60 & & Stenosis, dilatation and valvular regurgitation \\
\hline & $14 \mathrm{Y}$ & & $11 \mathrm{Y}$ & 25 & & None \\
\hline 7 & $7 \mathrm{Y}$ & $\mathrm{F}$ & $7 \mathrm{Y}$ & 60 & Calcifications & \\
\hline 8 & $22 \mathrm{Y}$ & M & $10 \mathrm{Y}$ & NA & Calcifications & \\
\hline 9 & $1 \mathrm{Y}$ & M & $1 \mathrm{Y}$ & 60 & None & \\
\hline \multirow[t]{2}{*}{10} & $10 \mathrm{Y}$ & M & $4 \mathrm{Y}$ & 70 & Calcifications & \\
\hline & $10 \mathrm{Y}$ & & $10 \mathrm{D}$ & 35 & None & \\
\hline \multirow[t]{2}{*}{11} & $12 \mathrm{y}$ & M & $6 \mathrm{M}$ & 37 & None & \\
\hline & $15 \mathrm{Y}$ & & $2 \mathrm{Y}$ & NA & Calcifications & \\
\hline 12 & $3 \mathrm{Y}$ & M & $1 \mathrm{M}$ & 10 & Plicature/twist & \\
\hline \multirow[t]{4}{*}{13} & $2 \mathrm{Y}$ & M & $7 \mathrm{M}$ & 60 & Dilatation & \\
\hline & $2 \mathrm{Y}$ & & $9 \mathrm{M}$ & 60 & Dilatation & \\
\hline & $4 \mathrm{Y}$ & & $3 \mathrm{Y}$ & 60 & & Stenosis and dilatation \\
\hline & $5 \mathrm{Y}$ & & $10 \mathrm{D}$ & 8 & None & \\
\hline 14 & $15 \mathrm{Y}$ & M & $4 \mathrm{Y}$ & 25 & Calcifications & \\
\hline \multirow[t]{2}{*}{15} & $9 \mathrm{Y}$ & $\mathrm{F}$ & $1 \mathrm{M}$ & 60 & Plicature/twist & \\
\hline & $16 y$ & & $6 \mathrm{Y}$ & 110 & Stenosis, plicature/twist and calcifications & \\
\hline 16 & $2 y$ & $\mathrm{~F}$ & $5 \mathrm{D}$ & 12 & None & \\
\hline 17 & $7 \mathrm{Y}$ & $\mathrm{F}$ & $5 \mathrm{Y}$ & 50 & $\begin{array}{l}\text { Dilatation, thrombus/vegetation and } \\
\text { calcifications }\end{array}$ & \\
\hline \multirow[t]{5}{*}{18} & $15 \mathrm{Y}$ & M & $1 \mathrm{M}$ & 75 & & Stenosis and plicature/twist \\
\hline & $15 \mathrm{Y}$ & & $1 \mathrm{M}$ & 28 & Stenosis, plicature/twist & \\
\hline & $15 \mathrm{Y}$ & & $1 \mathrm{M}$ & 31 & None & \\
\hline & $16 \mathrm{Y}$ & & $5 \mathrm{M}$ & 34 & None & \\
\hline & $17 \mathrm{Y}$ & & $2 \mathrm{Y}$ & 19 & Calcifications & \\
\hline 19 & $16 \mathrm{Y}$ & M & $1.5 \mathrm{Y}$ & 60 & $\begin{array}{l}\text { Stenosis, thrombus/vegetation and } \\
\text { calcifications }\end{array}$ & \\
\hline 20 & $17 \mathrm{Y}$ & $\mathrm{F}$ & $7 \mathrm{Y}$ & 27 & None & \\
\hline 21 & $1 \mathrm{Y}$ & M & $2 \mathrm{M}$ & NA & Stenosis and plicature/twist & \\
\hline 22 & $18 \mathrm{Y}$ & M & $2.5 \mathrm{y}$ & NA & None & \\
\hline 23 & $4 \mathrm{Y}$ & M & $4 \mathrm{Y}$ & 90 & Stenosis, dilatation and calcifications & \\
\hline 24 & $2 \mathrm{Y}$ & M & $2.5 \mathrm{Y}$ & 50 & & Stenosis, dilatation and valvular regurgitation \\
\hline
\end{tabular}

$N A$ not available 
Fig. 1 CT and MR images of a normal Contegra ${ }^{\circledR}$ in patient 11 . a CT sagittal MIP view shows the normal appearance of the Contegra $^{\circledR}$. Note the hardly depictable normal valve leaflets (arrow). b CT 3-D VR reconstruction shows a Contegra ${ }^{\circledR}$ with normal CT appearance. c Contrast-enhanced CT with axial MIP view shows a normal Contegra ${ }^{\mathbb{R}}$ with surgical clips at both extremities (arrows). d MRA, sagittal view, shows the normal MR appearance of a Contegra $^{\circledR}$. The valve leaflets are not visible
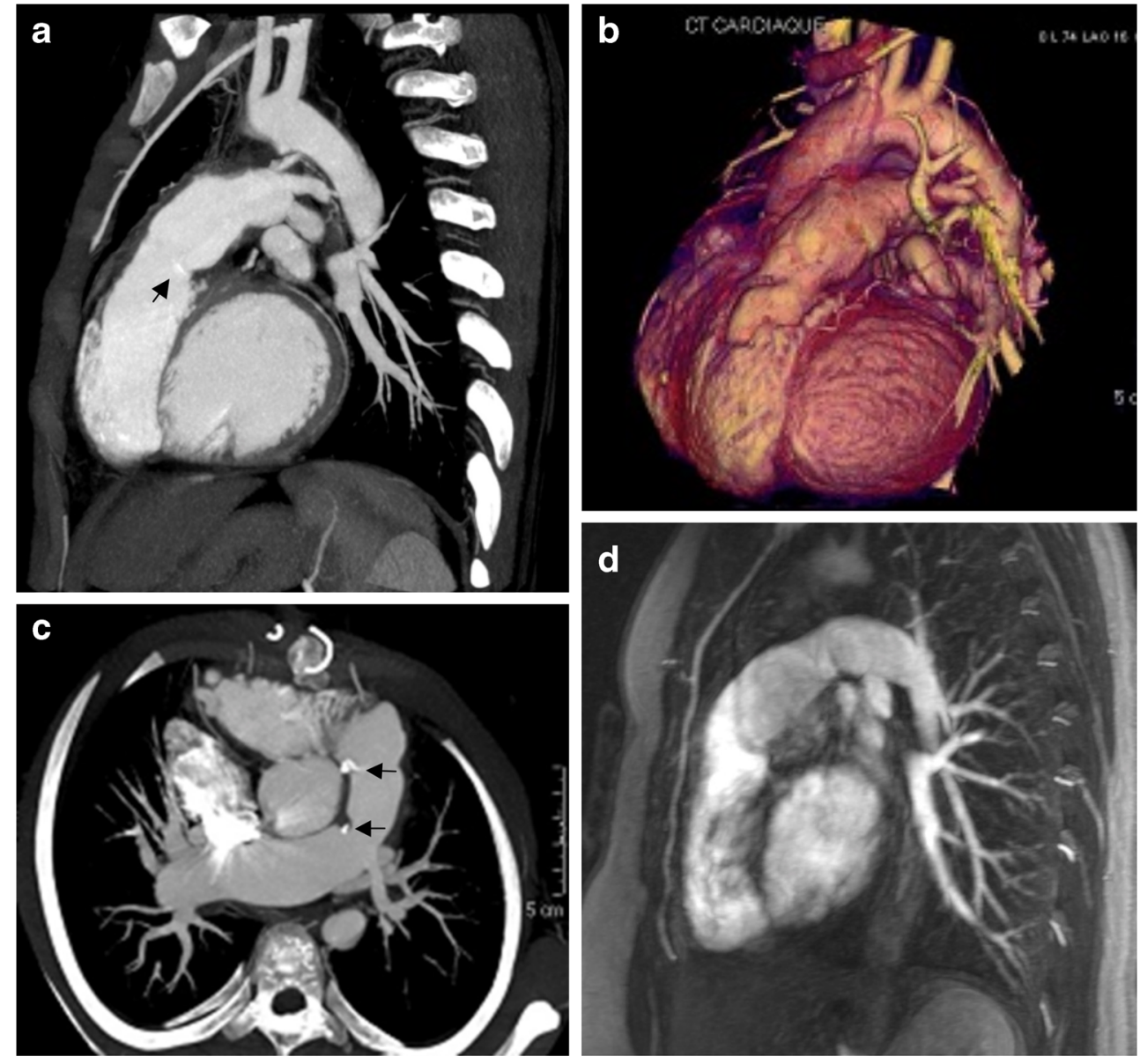

values were available for almost all patients. At echocardiography, the gradient through the conduit was considered significant if it was equal to or more than $50 \mathrm{mmHg}$. Patients with a visible stenosis on MR or CT always showed a significantly elevated gradient on US. The discrepancy between echography and CT for patient 18 is explained by the fact that the CT was performed just before reintervention and the echography right after reintervention. As for patient 6, the first echographic gradient was measured at $37 \mathrm{mmHg}$. A stenosis of the conduit was described on the MRI, but it was close to $50 \%$ and considered not significant at that time. The stenoses were often located at both extremities of the conduit (6/10 cases) except if secondary to infection (4/10 cases). In those cases, the stenosis was more global, due to parietal thickening caused by infection.

In two cases reported by Kadner et al. [10], the early apparition of stenosis was probably promoted by the presence of hypoplastic pulmonary arteries at the distal anastomosis of the conduit and by conduits of small calibre, which caused a disadvantageous turbulent flow pattern. We encountered a similar case in a patient with a twisted right pulmonary artery

Table 5 Type and number of complication with Contegra ${ }^{\circledR}$ and patient's age

\begin{tabular}{|c|c|c|c|c|}
\hline Mean patient's age (range) & Mean Contegra ${ }^{\circledR}$ 's age (range) & Type of complications & $\begin{array}{l}\text { Number of complications } \\
\text { (\% of exams) }\end{array}$ & $\begin{array}{l}\text { Number of patients per } \\
\text { complication }(\% \text { of } \\
\text { patients) }\end{array}$ \\
\hline 10.5 years (1 year-16 years) & 3.8 years (1 month-10 years) & Stenosis & $15(55.6 \%)$ & $10(41.7 \%)$ \\
\hline 5.1 years ( 2 years-12 years) & 3.9 years (1 month-9 years) & Dilatation & $8(30 \%)$ & $5(20.8 \%)$ \\
\hline 4.7 years (1 month-16 years) & 1.1 years (1 month-6 years) & Plicature/twist & $6(22.2 \%)$ & $4(16.6 \%)$ \\
\hline 11.5 years ( 7 years-16 years) & 3.3 years ( 1.5 years -5 years $)$ & Thrombus/vegetations & $2(7.4 \%)$ & $2(8.3 \%)$ \\
\hline 13.1 years ( 4 years-22 years) & 5 years ( 1.5 years-10 years) & Calcifications & $11(40.7 \%)$ & $11(45.8 \%)$ \\
\hline 6.4 years ( 2 years-10 years) & 6.5 years $(2.5$ years -10 years $)$ & Valvular regurgitation & $5(18.5 \%)$ & $3(12.5 \%)$ \\
\hline
\end{tabular}




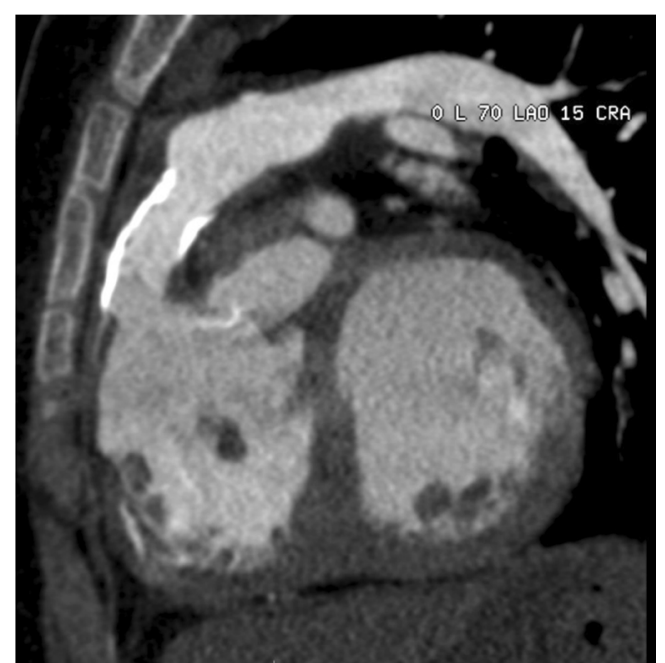

Fig. 2 CT with MIP reconstruction (sagittal view) shows a severely calcified Contegra ${ }^{\circledR} 7$ years after insertion in patient 7

who developed a severe stenosis of the distal Contegra ${ }^{\circledR}$ (Fig. 3).

A dilated Contegra ${ }^{\circledR}$ was found in five patients $(20.8 \%)$ (Fig. 4). It was associated with the presence of proximal stenosis in three cases and with post-infectious changes resulting from a healed endocarditis in the three others.

Plicature of the conduit was found in four cases (16.7\%). It was visible as a gathered aspect of the conduit's walls. Two of the patients presented with severe stenosis. The first one showed a hypoplasia of the left pulmonary arteries (Fig. 5) and the second one had a conduit placed in an extraanatomical location, causing the twist (Fig. 6).

Vegetations and thrombus on the Contegra ${ }^{\circledR}$ valve were seen in two CT examinations. The first had been referred for imaging on suspicion of pulmonary embolism and the second for mediastinitis, both in an infectious context. Intraluminal

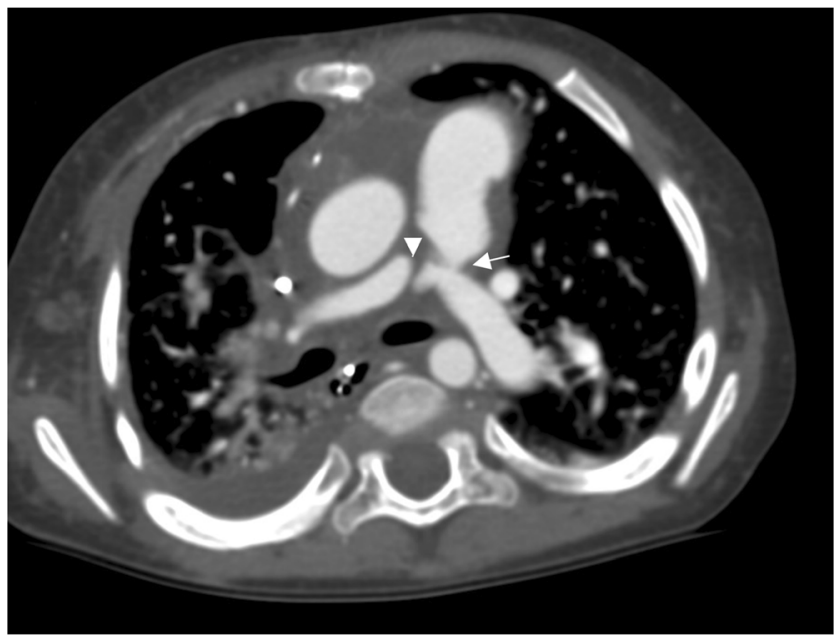

Fig. 3 Stenosis at the distal extremity of the Contegra ${ }^{\circledR}$ in patient 21. Axial contrast-enhanced CT shows the stenosed distal extremity of the conduit (arrow) and a twisted right pulmonary artery (arrowhead) thrombus of the conduit appeared as a hypodense parietal thickening. Vegetations were noticeable as a focal hypodense thickening of the valve leaflets (Fig. 7).

Significant valvular regurgitation was found in five MR exams (three patients), always confirming the diagnosis first made at echography.

A comparison between echographic gradient and MR or CT findings showed a good correlation between both techniques to evaluate the Contegra ${ }^{\circledR}$ lumen reduction. In patients with a gradient equal or superior to $60 \mathrm{mmHg}$ on echography, the Contegra ${ }^{\circledR}$ was almost always stenosed or calcified $(80 \%$ of the cases). In two cases, a gradient superior to $60 \mathrm{mmHg}$ was found on echography, but no clear stenosis of the Contegra ${ }^{\circledR}$ could be depicted on CT (patients 9 and 13). For patient 9 , the gradient was $60 \mathrm{mmHg}$ and no stenosis of the Contegra $^{\circledR}$ was visible. However, this patient had a stenosis of a pulmonary artery. After stenting of this artery, the gradient returned to normal. Case number 13 had a dilated but not really stenosed Contegra ${ }^{\circledR}$. The significant echographic gradient probably was explained by vegetations that were visible only with US.

In our study, nine patients underwent cardiac catheterization. In seven cases, the reason was the implantation of a new valve (five patients)/stent (one patient) in the Contegra ${ }^{\circledR}$ or in a pulmonary artery (one patient). For the two remaining patients, angiocardiograms were performed as a preoperative assessment, one after CT and one after MRI. For those studies, results were concordant.

\section{Discussion}

During the last decade, various prosthetic conduits have been used for the reconstruction of RVOT in congenital cardiac anomalies. The Contegra ${ }^{\circledR}$ valved conduit is one of them. It is available in all sizes between 12 and $22 \mathrm{~mm}$ of internal diameter, something that constitutes a major advantage over homografts, especially for paediatric patients who require small diameter conduits. Short-term results have shown promising results with Contegra ${ }^{\circledR}$ compared to other xenografts $[6$, 11]. After implantation, the first evaluation is generally made using echography. However CT and MRI have become increasingly used in both the immediate postoperative assessment and in the long-term follow-up of congenital cardiac malformations [8, 12]. Nonetheless, as far as we know, the radiological appearance (with $\mathrm{CT}$ and MR) of the normal Contegra $^{\circledR}$ and its specific complications have never been described. With this study, we hope to define the normal imaging of the Contegra ${ }^{\circledR}$ conduit and to describe important items that should be examined in the work-up of these patients.

In our institution, CT and MRI are additional imaging methods, never performed before echography. Both 
Fig. 4 A dilated Contegra ${ }^{\circledR}$ with stenosis at both extremities in patient 6. a MRA axial MIP view shows the stenosis at both extremities of the Contegra ${ }^{\circledR}$ (arrows) b Reconstruction of a contrast-enhanced CT shows the dilatation in the middle of the Contegra $^{\circledR}$ (arrow). Coronal (c) and (d) sagittal arteriography views confirm the finding on $\mathrm{CT}$
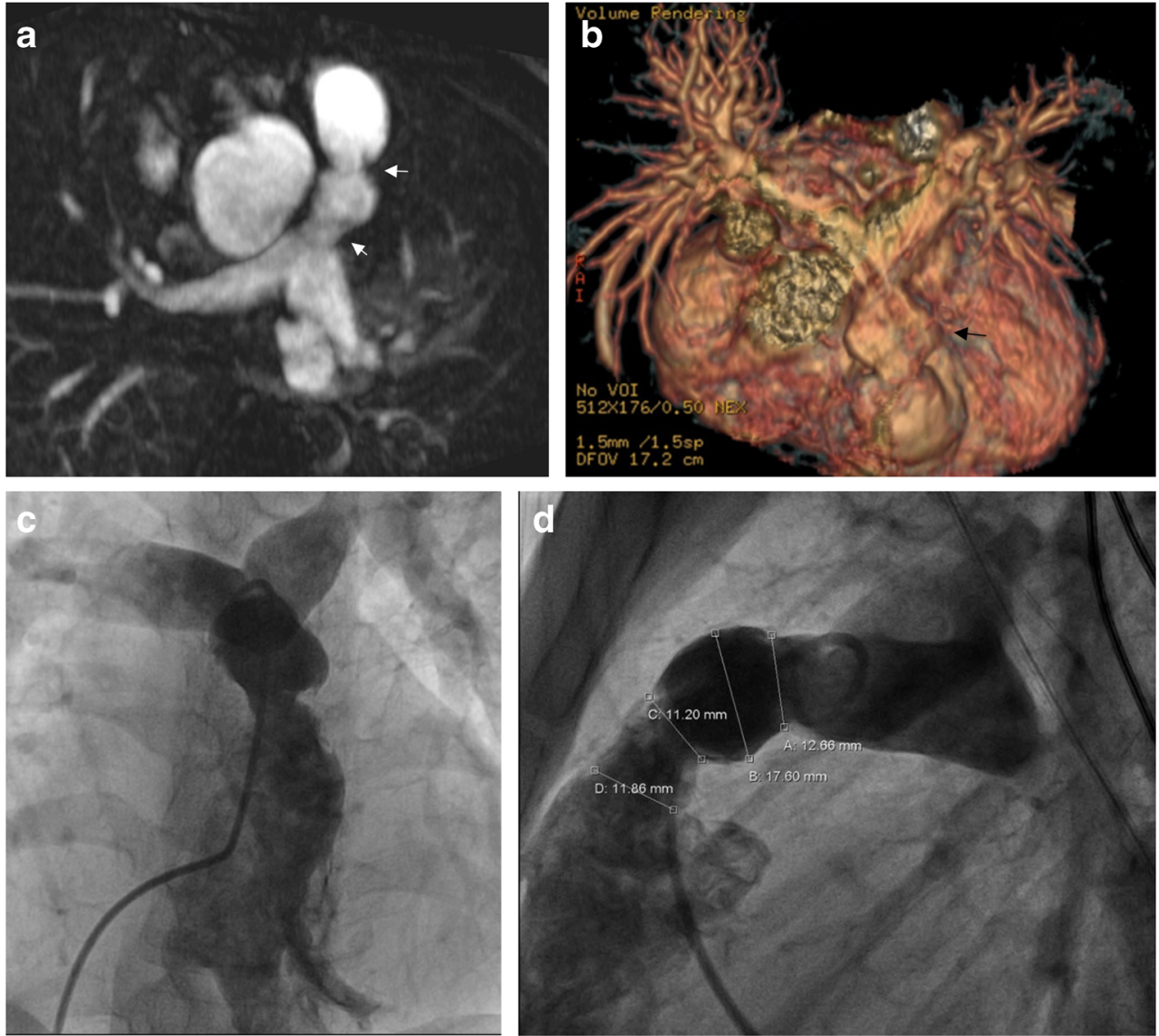

techniques are less invasive than transoesophageal echography or arteriography and are not operator-dependent. Generally, CT and MR are requested by the paediatric cardiologists or the cardiovascular surgeon to answer a specific question concerning measurements and anatomy or to confirm a suspected complication such as pulmonary embolism, endocarditis or pulmonary regurgitation. Both studies appear to be very helpful before and after an endovascular procedure, especially when echocardiography is suboptimal due to patient anatomy or postoperative changes. However, it is always important to discuss the position of the conduit with the surgeons because different implantation techniques exist depending on the type of cardiac malformation and the patient anatomy.

In an initial assessment, CT and MRI may bring additional information about coexisting pathologies and concomitant anomalies, displaying the pulmonary vessels and the aorta. For example, in one of our cases, a CT performed to assess endocarditis complications showed not only a Contegra ${ }^{\circledR}$ stenosis with valvular leaflet thickening but also a pulmonary embolism (case 17).

In follow-up studies, CT and MRI enable an objective comparison of various examinations of the same patient.
Fig. 5 A twisted Contegra ${ }^{\circledR}$ in a patient with a hypoplastic left pulmonary artery in patient 12 . a Axial contrast-enhanced CT depicts the plicature (arrow). b 3D VR reconstruction of the contrast-enhanced CT shows the kinked Contegra ${ }^{\circledR}$ (arrow)
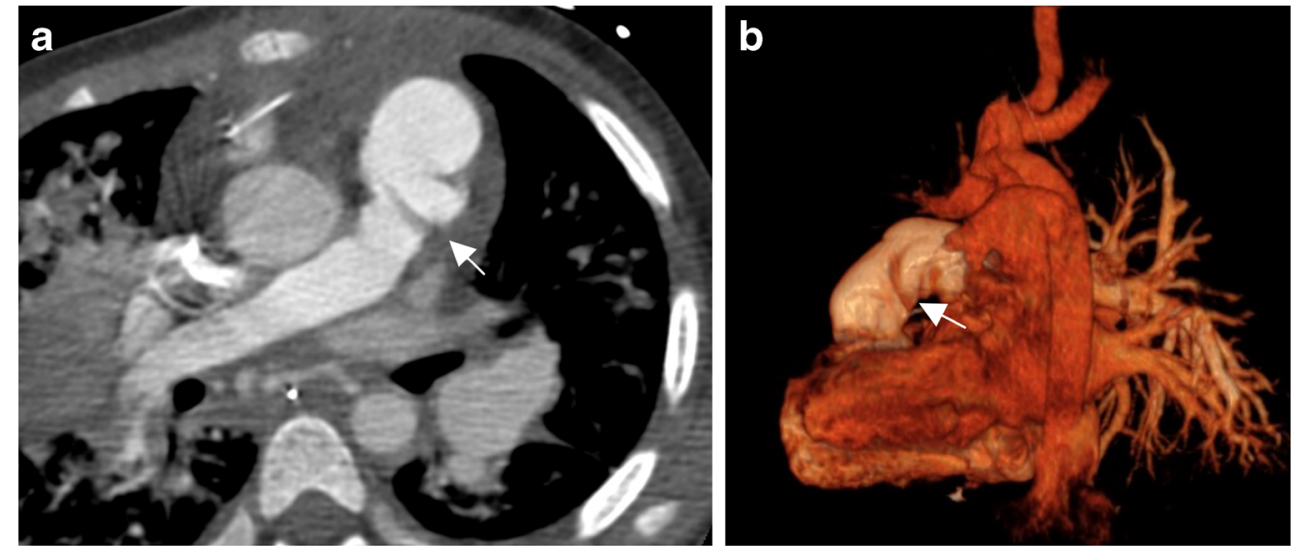
Fig. 6 Twisted Contegra ${ }^{\circledR}$ in patient 18. a Contrast-enhanced CT with VR reconstruction shows the twisted Contegra ${ }^{\circledR}$ placed in an extra-anatomical location because of an aberrant coronary origin. b Contrast-enhanced CT with oblique MIP view shows the twisted Contegra ${ }^{\circledR}$. c VR reconstruction of a contrastenhanced CT shows the twisted Contegra ${ }^{\circledR}$ after stenting. d Oblique MIP view of a contrastenhanced CT shows the stent in the twisted Contegra ${ }^{\circledR}$ (arrow)
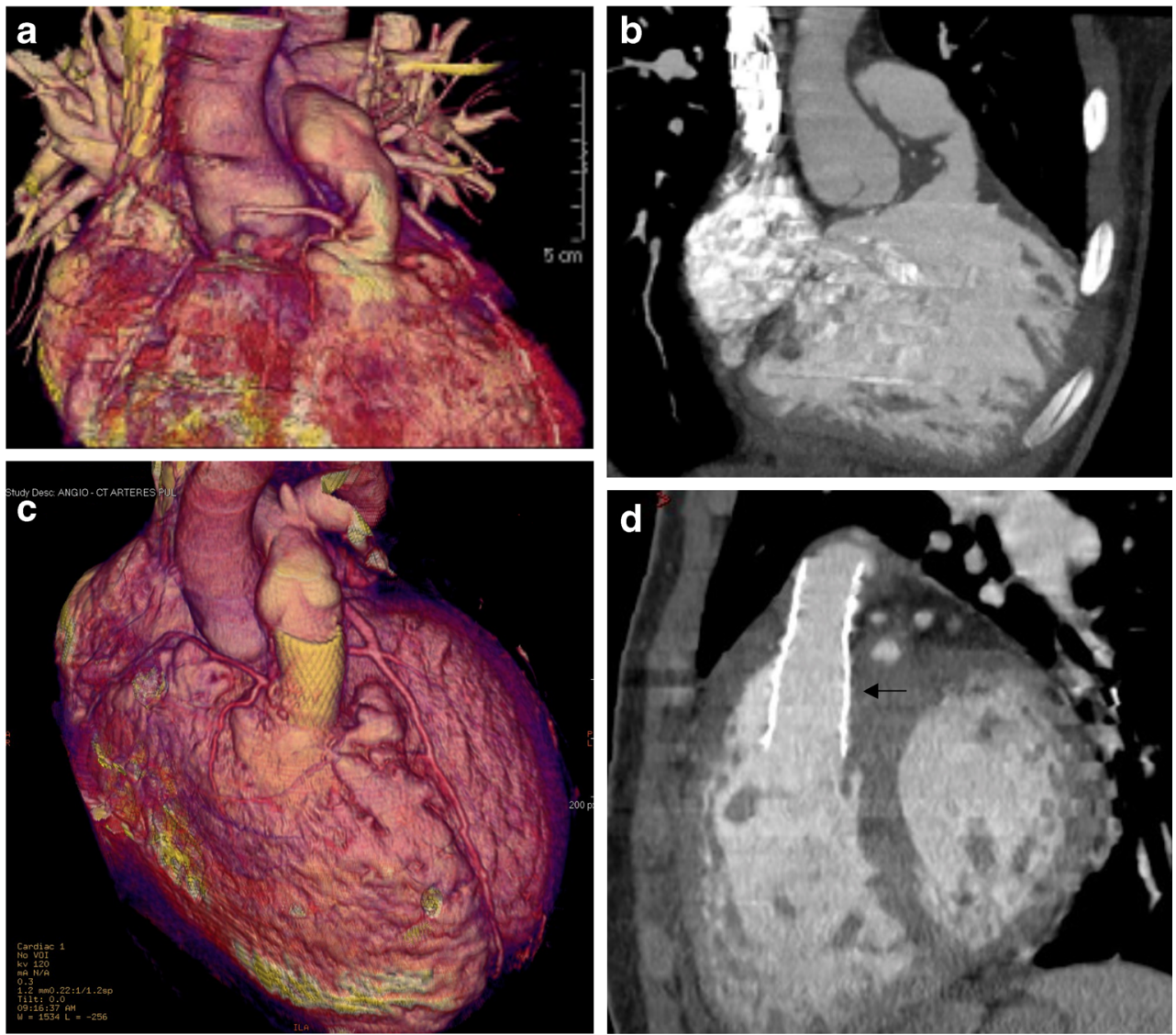

CT provides images of excellent spatial resolution in a fast acquisition time and it is generally available quickly. Sometimes, exact localization of the stenosis site can be difficult with echography, because of the small distance between the conduit valve and the pulmonary artery bifurcation [13]. In those cases, CT proves to be of significant help. It is increasingly preferred to catheter angiography, also because it offers 3 -D volume data in a noninvasive way. Consequently, a wellconducted CT examination may delay or replace angiography. Nevertheless, high radiation doses and contrast medium causing kidney burden are the major drawbacks of CT [14]. In our institution, ECG-gated CTs are done in a retrospective mode, only when a high cardiac frequency precludes prospective acquisitions. In general, beta-blockers are used to lower and stabilize the heart rate. When cardiac rhythm remains stable between 55 and $75 \mathrm{bpm}$, a prospective acquisition is selected. Otherwise, we choose retrospective acquisition. Gated CT is performed only when depiction of small structures, such as the coronary arteries, is necessary. Usually, if the question involves great vessel anatomy and Contegra ${ }^{\circledR}$ permeability, a non-gated $\mathrm{CT}$ is considered sufficient. With gated $\mathrm{CT}$, the major benefit was a clear depiction of the RVOT walls,
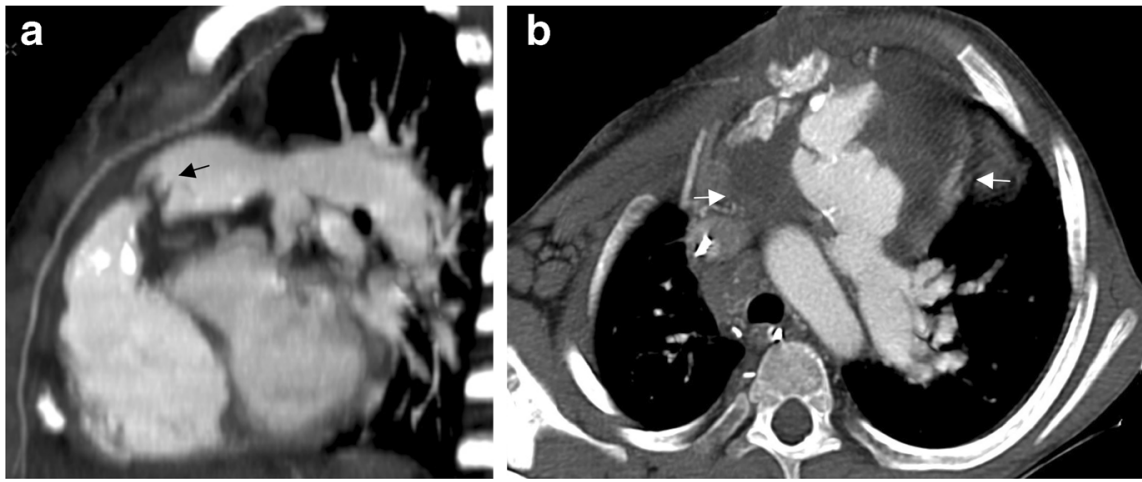

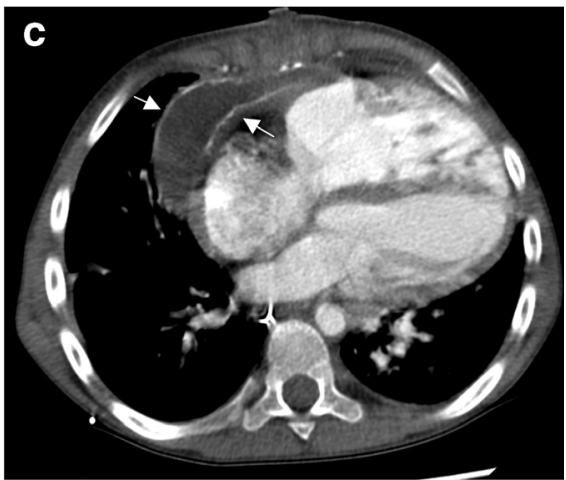

Fig. 7 Endocarditis with mediastinitis in patient 17. a Contrast-enhanced CT with sagittal MIP view shows the thickened valve leaflets (arrow). b Axial oblique MPR reconstruction of a contrast-enhanced CT shows the mediastinal collection surrounding the Contegra ${ }^{\circledR}$ (arrows). c Axial view of a contrast-enhanced CT shows the parietal enhancement of the collection (arrows) 
without motion artefacts. Gating was helpful in measuring the true lumen of the Contegra ${ }^{\circledR}$ and avoided over- or underestimation of a potential stenosis. However, this is a retrospective study up to 1999, at the beginning of cardiac CT. It explains the important DLP values obtained for gated CT, especially the retrospective ones. Up-to-date recommendations state that in the paediatric population, cardiac CT should now be acquired at 80 or even $70 \mathrm{kV}$. Prospective imaging should also be favoured. If retrospective CT is performed, it should be acquired with a monophasic acquisition, preferentially at systolic phase to decrease motion artefacts. This significantly reduces the radiation dose [15].

MRI is a noninvasive non-ionising technique, valuable for functional and anatomical evaluation. In addition, in case of valve failure, MRI might provide more reliable data on valvular regurgitation and ventricle volumes than echography. MRI is also valuable for planning catheter-guided interventions [16]. Nonetheless, it is less easily available and more expensive than $\mathrm{CT}$ or echography. It is also time-consuming and always requires sedation.

Previous studies have reported that the bovine jugular graft was free of calcification even several years after implantation $[3,4,17]$. Breymann et al. [4] described mild calcifications after a 5-year follow-up using standardised echocardiography, in only 8 examinations out of 165 patients. However, we were surprised to find an important number of calcified conduits ( $42 \%$ of CT examinations), some of them being severely affected only 2.5 years after implantation. This may be because of the selection bias present in our study because cardiologists had mostly referred patients with bad evolution for additional imaging studies and because $\mathrm{CT}$ is probably more sensitive than echography in the detection of conduit wall calcifications.

In our series, four CT exams and one MR showed a twisted Contegra ${ }^{\circledR}$. Both MR and CT were able to depict a plicature of the Contegra ${ }^{\circledR}$ (patient 18). However, plicatures have rarely been described in the literature. To our knowledge, the only mention of a twisted Contegra ${ }^{\circledR}$ comes from Corno et al. [17]. $\mathrm{CT}$ and MR allow detection and precise measurements of stenosis. For Shoenhoff and coworkers [11], the first cause of graft failure was progressive stenosis with frequent formation of a stenotic membrane at the distal anastomosis. Other reports also emphasized the presence of stenosis at the pulmonary anastomosis imputed to excessive intimal peel formation and perigraft scarring $[18,19]$.

We also found two patients with a stenosed conduit after a Ross operation for aortic stenosis, even if this type of procedure is said to carry less risk of Contegra ${ }^{\circledR}$ stenosis. The lower risk is attributed to the fact that, in patients with aortic stenosis, the pulmonary arteries are normal and the conduit is larger [4].

For Iyer [20], the wall of the Contegra ${ }^{\circledR}$ tends to be thicker than the wall of the native pulmonary arteries causing a difficulty in anastomosing them. This could also lead to early distal stenosis.
Another factor that can be associated with early stenosis of the Contegra ${ }^{\circledR}$ is an insufficient rinsing of the conduit before implantation: Remnants of glutaraldehyde storage solution could indeed accelerate stenosis [4].

Gradient elevation inside the conduit was found in case of pulmonary embolism or significant lumen reduction of the Contegra ${ }^{\circledR}$ at CT or MRI and showed a good correlation with echographic findings. However, in young or restless children, the echographic gradient can be overestimated when the child is not sedated. For this reason, it is always important to be aware of the exam conditions when there is a discrepancy between echography and the other modalities.

The association between the presence of isolated calcifications and a high echographic gradient could not be demonstrated. Then, even if calcifications were frequently noted, they were rarely responsible for a significant stenosis when isolated.

A few cases of aneurysmal dilatation of the Contegra ${ }^{\circledR}$ have been described in the literature [21]. The dilatation can be limited to the sites of anastomosis [13,22] or it can concern the entire conduit [23]. In our cohort, we found some dilated conduits, but the dilatation was always associated with immediate proximal stenosis, if not due to infection. The most striking case was a string-of-beads stenosis with a succession of stenosis and dilatations. We then considered that dilatations of the conduit were mainly the result of pre-existing stenosis.

Infection is a major risk factor for the early aging of the conduit. The patients with history of endocarditis presented with a severely distorted Contegra ${ }^{\circledR}$ such as a thickened valve leaflet, inspissated conduit walls and parietal calcifications. Those changes were principally detected with CT studies in our series. CT and MRI are also valuable when infection is suspected because they clearly depict mediastinal collections in cases of superimposed mediastinitis (Fig. 8). Tiete [13] reported a patient with a fibrinous membrane inside the Contegra $^{\circledR}$, most likely caused by thrombus formation that could be peeled off from the conduit wall. We found a similar case (patient 19) presenting with endocarditis where CT also depicted a membrane that was subsequently confirmed at

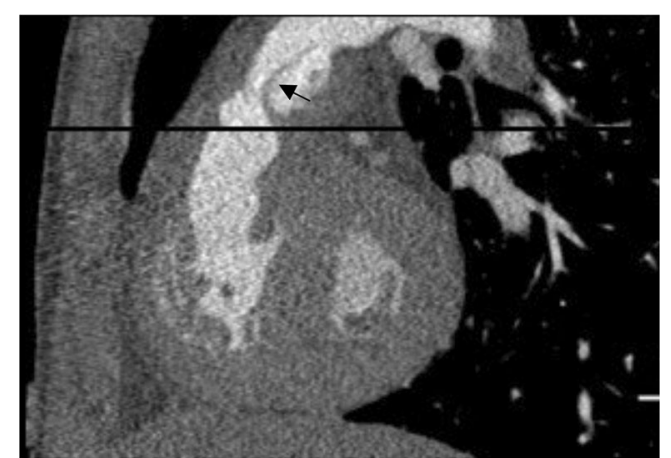

Fig. 8 Endocarditis in patient 19. Cardiac-gated CT, sagittal view, shows a hypodense membrane inside the Contegra ${ }^{\circledR}$ (arrow) 
echography and that could correspond to a fibrinous membrane (Fig. 8).

One advantage of the Contegra ${ }^{\circledR}$ conduits resides in its high pliability $[13,18]$. Yet, it can also prove to be a serious inconvenience in certain circumstances. In our series, plicature or even complete twist of the conduit could be seen on 3-D VR reconstructions in four patients. This finding provided an explanation for the appearance of early stenosis, which, in fact, was due to the morphology of the conduit and not to parietal changes. In each of these four patients, the twisted and plicatured Contegra ${ }^{\circledR}$ was ascribed to severe stenosis of the pulmonary arteries or to difficulties at the time of implantation.

Valvular regurgitation was confirmed by MR in two patients. This complication is classical and has been prospectively studied by Nordmeyer et al. [24] in homografts inserted in the pulmonary position. For Nordmeyer, homograft distortion is linked to a negative functional outcome. In our patients, conduits with an insufficient valve were not twisted but markedly stenosed.

Valve insertion in the event of valve failure or implantation of a stent in case of conduit stenosis constitutes major progress compared to immediate graft replacement. Chronic right ventricle overload is associated with dysfunction and sudden death. Percutaneous pulmonary valve implantation improves RVOT hemodynamic and delays surgery by prolonging the conduit lifespan [25]. Procedural results are excellent with a $6 \%$ procedural complication rate in specialized centres. For Lurz et al. [26] the major complication is stent fractures (20\% of the cases) warranting close surveillance and sometimes second device insertion. CT and angio-MR enable accurate planning before catheter intervention [16]. For example, our patient 10 had a stenosed valve, visible on CT by the presence of thin calcifications involving the valvular leaflets. After implantation of a Sapien ${ }^{\circledR}$ valve, the echographic gradient returned to normal (Fig. 9). In another example of a twisted Contegra ${ }^{\circledR}$ (patient 18), the conduit had been inserted in an unusual location because of an anomalous right coronary artery origin: The conduit had been implanted inside the native pulmonary trunk instead of in an extracardiac position. CT images showed well the extremely twisted conduit causing a significant stenosis of the lumen (Fig. 5). After stenting, the echographic gradient lowered from 75 to $28 \mathrm{mmHg}$ and CT showed no residual stenosis. Furthermore, it is interesting to note that the twist is displayed much easier in 3-D MPR reconstructions.

In our series, factors associated with early aging of the conduit and likely to cause complications, such as endocarditis, size of the pulmonary vessels, type of anastomosis and implantation techniques, were well depicted by both $\mathrm{CT}$ and MR. Some other factors, also causing conduit aging, are not visible with imaging: the suturing technique, intraoperative handling of the Contegra ${ }^{\circledR}$ and selection of size. For all its limitations, the Contegra ${ }^{\circledR}$ is not always the conduit of choice for many surgeons [20]. However, as long as nothing better is found, the paediatric radiologist will be confronted with the imaging of those conduits. When evaluating those conduits, the radiologist has to keep in mind that the best modality to depict twist or calcifications is $\mathrm{CT}$ and that MR is the gold standard for flow and ventricular function measurements.

This study has some limitations. First, it is a retrospective study with a heterogeneous group of patients and examinations. Secondly, it deliberately concentrates on one type of conduit, the Contegra ${ }^{\circledR}$, putting aside homografts, xenografts and other prosthetic conduits. There is also a selection bias, as the patients referred for additional imaging work-up were generally those with suspected complications. This fact explains the discrepancies with results of other studies in terms
Fig. 9 Two different patients with a valve inserted inside the Contegra ${ }^{\circledR}$. a CT with sagittal view shows a Sapien ${ }^{\mathbb{R}}$ valve (arrow) implanted in a previously stenosed Contegra $^{\circledR}$ in patient 10. b MR steady-state fast precession sagittal view shows a Sapien ${ }^{\circledR}$ valve implanted in a previously stenosed Contegra ${ }^{\circledR}$ in patient 1. Note the artefacts caused by the valve (arrow)
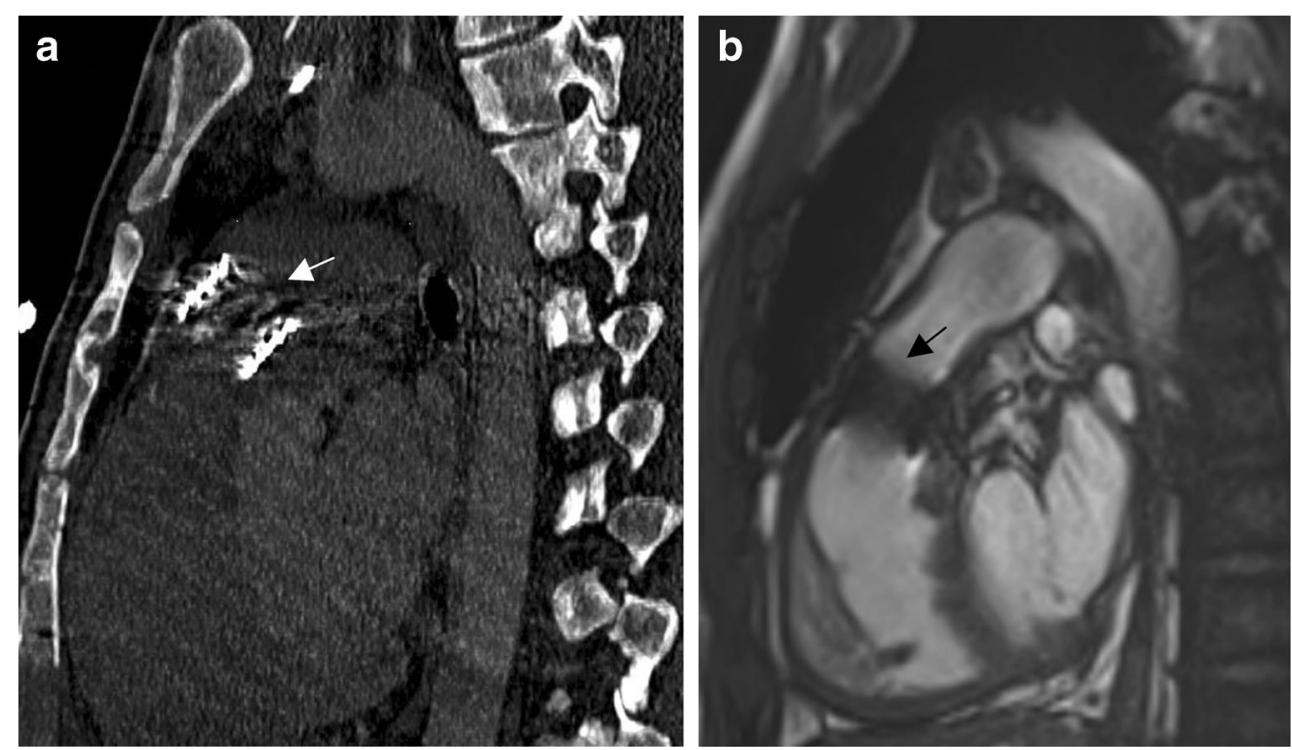
of complication rates. As the study is retrospective, hemodynamic values of the valve were not routinely assessed with MR at that time. In the future, it would be interesting to compare CT and MR. This would be possible only in a prospective study. Finally, as the Contegra ${ }^{\circledR}$ is a biological conduit, it is not yet possible to know if every conduit has the same physical and aging properties.

\section{Conclusion}

The quick availability and great accessibility has made $\mathrm{CT}$ an essential imaging technique when assessing congenital heart disease. It enables the acquisition of high spatial resolution images in a short scanning time, generally avoiding sedation. Likewise, MRI has become of prime importance when evaluating cardiac function and flow measurements. After Contegra ${ }^{\circledR}$ implantation, there are benefits to using both techniques. Even if echography remains the primary imaging study, if it is inconclusive, CT and MR bring additional information about permeability and postoperative anatomy. They make it possible to depict the normal radiological appearance of the conduit, and allow comparison and a precise evaluation of any changes in the follow-up period. In the search for complications, they clearly identify stenosis and dilatations, which should always be described compared to the original diameter of the conduit, i.e. before implantation. Calcifications and fibrous membranes are also more visible compared to echography. Evaluation of pulmonary vessels distal to the conduit is made much easier. In addition, 3-D and MPR reconstructions seem to be helpful in assessing graft twist. Moreover, CT is highly sensible in showing calcification and valve leaflets thickening occurring after endocarditis. Finally, 2-D and 3-D reconstructions are very helpful in planning catheter-guided interventions in case of valve implantation or Contegra ${ }^{\circledR}$ stenting. The capacity of MR and CT imaging to precisely depict the position of the stent or the newly implanted valve is highly valuable during the postoperative period.

\section{Conflicts of interest None}

\section{References}

1. Homann M, Haehnel JC, Mendler N et al (2000) Reconstruction of the RVOT with valved biological conduits: 25 years experience with allografts and xenografts. Eur J Cardiothorac Surg 17: 624-630

2. Food and Drug Administration (2003) Food and Drug Administration, Rockville. Available via http://www.accessdata.fda. gov/cdrh_docs/pdf2/H020003a.pdf. Accessed 21 May 2012
3. Sekarski N, van Meir H, Rijlaarsdam ME et al (2007) Right ventricular outflow tract reconstruction with the bovine jugular vein graft: 5 years' experience with 133 patients. Ann Thorac Surg 84:599-605

4. Breymann T, Blanz U, Wojtalik MA et al (2009) European Contegra ${ }^{\circledR}$ multicentre study: 7-year results after 165 valved bovine jugular vein graft implantations. Thorac Cardiovasc Surg 57:257269

5. Bové T, Demanet H, Wauthy PE et al (2002) Early results of valved bovine jugular vein conduit versus bicuspid homograft for right ventricular outflow tract reconstruction. Ann Thorac Surg 74:536541

6. Fiore AC, Brown JW, Turrentine MW et al (2011) A bovine jugular vein conduit: a ten-year bi-institutional experience. Ann Thorac Surg 92:183-190

7. Meng H, Grosse-Wortmann L (2012) Gadolinium in pediatric cardiovascular magnetic resonance: what we know and how we practice. J Cardiovasc Magn Reson 14:56

8. Kellenberger CJ, Yoo SJ, Büchel ER (2007) Cardiovascular MR imaging in neonates and infants with congenital heart disease. Radiographics 27:5-18

9. Chen JJ, Manning MA, Frazier AA et al (2009) CT angiography of the cardiac valves: normal, diseased, and postoperative appearances. Radiographics 29:1393-1412

10. Kadner A, Dave H, Stallmach T et al (2004) Formation of a stenotic fibrotic membrane at the distal anastomosis of bovine jugular vein grafts $\left(\right.$ Contegra $\left.{ }^{\circledR}\right)$ after right ventricular outflow tract reconstruction. J Thorac Cardiovasc Surg 127:285-286

11. Schoenhoff FS, Loup O, Gahl B et al (2011) The Contegra ${ }^{\circledR}$ bovine jugular vein graft versus the Shelhigh pulmonic porcine graft for reconstruction of the right ventricular outflow tract: a comparative study. J Thorac Cardiovasc Surg 141:654-661

12. Leschka S, Oechslin E, Husmann L et al (2007) Pre- and postoperative evaluation of congenital heart disease in children and adults with 64-section CT. Radiographics 27:829-846

13. Tiete AR, Sachweh JS, Roemer U et al (2004) Right ventricular outflow tract reconstruction with the Contegra ${ }^{\mathbb{R}}$ bovine jugular vein conduit: a word of caution. Ann Thorac Surg 77: 2151-2156

14. Tsai IC, Chen MC, Jan SL et al (2008) Neonatal cardiac multidetector row CT: why and how we do it. Pediatr Radiol 38:438-451

15. Paul JF, Rohnean A, Sigal-Cinqualbre A (2010) Multidetector CT for congenital heart patients: what a paediatric radiologist should know. Pediatr Radiol 40:869-875

16. Valsangiacomo Büchel ER, DiBernardo S, Bauersfeld U et al (2005) Contrast-enhanced magnetic resonance angiography of the great arteries in patients with congenital heart disease: an accurate tool for planning catheter-guided interventions. Int J Cardiovasc Imaging 21:313-322

17. Corno AF, Qanadli SD, Sekarski N et al (2004) Bovine valved xenograft in pulmonary position: medium-term follow-up with excellent hemodynamics and freedom from calcification. Ann Thorac Surg 78:1382-1388

18. Göber V, Berdat P, Pavlovic M et al (2005) Adverse midterm outcome following RVOT reconstruction using the Contegra ${ }^{\circledR}$ valved bovine jugular vein. Ann Thorac Surg 79:625-631

19. Meyns B, Van Garsse L, Boshoff D et al (2004) The Contegra ${ }^{\circledR}$ conduit in the right ventricular outflow tract induces supravalvular stenosis. J Thorac Cardiovasc Surg 128:834-840

20. Iyer KS (2012) The Contegra ${ }^{\circledR}$ bovine jugular valved conduit: Living up to expectations? Ann Pediatr Cardiol 5:34-35

21. Delmo-Walter EM, Alexi-Meskishvili V, Abdul-Khaliq $\mathrm{H}$ et al (2007) Aneurysmal dilatation of the Contegra ${ }^{\circledR}$ bovine jugular vein conduit after reconstruction of the right ventricular outflow tract. Ann Thorac Surg 83:682-684 
22. Boudjemline Y, Bonnet D, Agnoletti G et al (2003) Aneurysm of the right ventricular outflow following bovine valved venous conduit insertion. Eur J Cardiothorac Surg 23:122-124

23. Bautista-Hernandez V, Kaza AK, Benavidez OJ et al (2008) True aneurysmal dilatation of a Contegra ${ }^{\circledR}$ conduit after right ventricular outflow tract reconstruction: a novel mechanism of conduit failure. Ann Thorac Surg 86:1976-1977

24. Nordmeyer J, Tsang V, Gaudin R et al (2009) Quantitative assessment of homograft function 1 year after insertion into the pulmonary position: impact of in situ homograft geometry on valve competence. Eur Heart J 30:2147-2154

25. Palma G, Giordano R, Russolillo V et al (2011) Percutaneous pulmonary valve implantation after endocarditis of Contegra ${ }^{\circledR}$ valved conduit: a case report. Thorac Cardiovasc Surg 59: $123-125$

26. Lurz P, Bonhoeffer P, Taylor AM (2009) Percutaneous pulmonary valve implantation: an update. Expert Rev Cardiovasc Ther 7:823833 